\title{
Relationship among Parenting Behavior, SES, Academic Achievement and Psychosocial Functioning in Peruvian Children*
}

\author{
Relación entre el comportamiento parental, SES, logro \\ académico y funcionamiento psicosocial en niños peruanos
}

Recibido: abril 9 de 2013| Revisado: agosto 3 de 2013 | Aceptado: octubre 3 de 2013

\author{
Denisse Lisette MANRIQUe Millones ** \\ POL GHESQUIÈRE *** \\ KARLA VAN LEEUWEN ***** \\ Katholieke Universiteit Leuven, Bélgica
}

doi:10.11144/Javeriana.UPSY13-2.rpba

Para citar este artículo: Manrique, D. L., Ghesquière, P., \& Van Leeuwen, K. (2014). Relationship among parenting behavior, SES, academic achievement and psychosocial functioning in Peruvian children. Universitas Psychologica, 13(2), 639-650. doi:10.11144/Javeriana.UPSY13-2.rpba

* Artículo de investigación

** Parenting and Special Education Research Unit. https://lirias.kuleuven.be/cv?u=U0056603. E-mail: denissemanriquemillones@gmail.com

**** http://www.kuleuven.be/wieiswie/nl/person/00004944. Full professor Faculty of Psychology and Educational Sciences. Manager of the Humanities and Social Sciences Doctoral School. Research coordinator of the Humanities and Social Sciences Group.E-mail: pol.ghesquiere@ppw.kuleuven.be

***** Associate Professor Faculty of Psychology and Educational Sciences. http://www.kuleuven.be/ wieiswie/en/person/00055523. E-mail: karla.vanleeuwen@ppw.kuleuven.be

\begin{abstract}
A B S T R A C T
This study addresses how Negative Parental Control (NPC) and Positive Parenting (PP) are associated with achievement in spelling, arithmetic or reading, socio-economic status (SES) and psychosocial factors such as selfworth (SW) and behavioral problems (BP). The sample is formed by 587 children attending $6^{\text {th }}$ grade of regular primary school and their families living in the urban zones of Metropolitan Lima, Peru. Structural Equation Modeling was used to analyze the hypothesized relations. Four models were built combining parenting dimensions and psychosocial factors. All models showed a good fit. Results showed a strong positive relationship between SES and achievement, and between SES and parenting. Strong associations between psychosocial factors and achievement were found. Implications are discussed about the role of SES on families and achievement but also about the role of parenting in children's psychosocial functioning.

Keywords

Academic achievement, SEM, psychosocial factors, socioeconomic status, Peru.

\section{RESUMEN}

Este estudio aborda cómo el Control Parental Negativo (NPC) y la Crianza Positiva (PP) están asociados con el logro en la ortografía, aritmética o la lectura, el nivel socioeconómico (SES) y factores psicosociales como selfworth (SW) y problemas de conducta (BP). La muestra estuvo formada por 587 niños que asistían a sexto grado de la escuela primaria regular y sus familias que viven en las zonas urbanas de Lima Metropolitana, Perú. Se utilizó el modelo de ecuaciones estructurales para analizar las relaciones hipotéticas. Se construyeron cuatro modelos que combinan dimensiones parentales y factores psicosociales. Todos los modelos mostraron un buen ajuste. Los resultados mostraron una relación positiva alta entre el SES y el logro, y entre SES y la crianza de los hijos. Se encontraron asociaciones fuertes entre los factores psicosociales y de logro. Se discuten las implicaciones sobre el papel de SES en las familias y los logros además del papel de la crianza de los hijos en el funcionamiento psicosocial de los niños.

Palabras clave autores

Logro académico, SEM, factores psicosociales, estatus socioeconómico, Perú.
\end{abstract}


Parents affect their children's development in different ways, by supporting trajectories through proactive behavior (e.g. encouragement), through mediation (e.g. help children to interpret challenging circumstances), or by reacting to children's characteristics (e.g. talents and weaknesses). In the bi-directional process of parenting, in which caregivers influence the behavior of their offspring and vice versa, many variables need to be considered. Within this process, parenting needs to be viewed as embedded within a set of contexts (including culture and socioeconomic status ([SES]; Leyendecker, Harwood, Comparini, \& Yalcinkaya, 2005), as well as child variables like academic achievement (Keegan, 2005) and psychosocial factors (Bean, Bush, McKenry, \& Wilson, 2003). The purpose of this study is to examine the relationships among academic achievement, psychosocial functioning and parenting practices in a Peruvian sample, a context in which this kind of research has never been done.

In our study we explore how SES as a context variable is related to parenting, academic achievement and psychosocial factors. We further investigate how positive parenting and negative behavioral control as dimensions of parenting mediate the association between SES and child psychosocial (self-worth and behavioral problems) and academic outcomes (see Figure 1).

We assume that psychosocial functioning is related to academic achievement. The hypothesized associations are discussed in more detail in the following sections.

\section{Parenting and Child Outcomes}

\section{Psychosocial Factors}

Studies on large samples confirm the positive association between diverse aspects of parenting and different measures of child psychosocial outcome, concurrently as well as predictively (Mewse, Eiser, Slater, \& Lea, 2004).

\section{Self-Worth}

Global self-worth is assessed by tapping the degree to which one is satisfied with one's life and feels positive toward oneself rather than combining additively the responses of self-appraisal in specific life

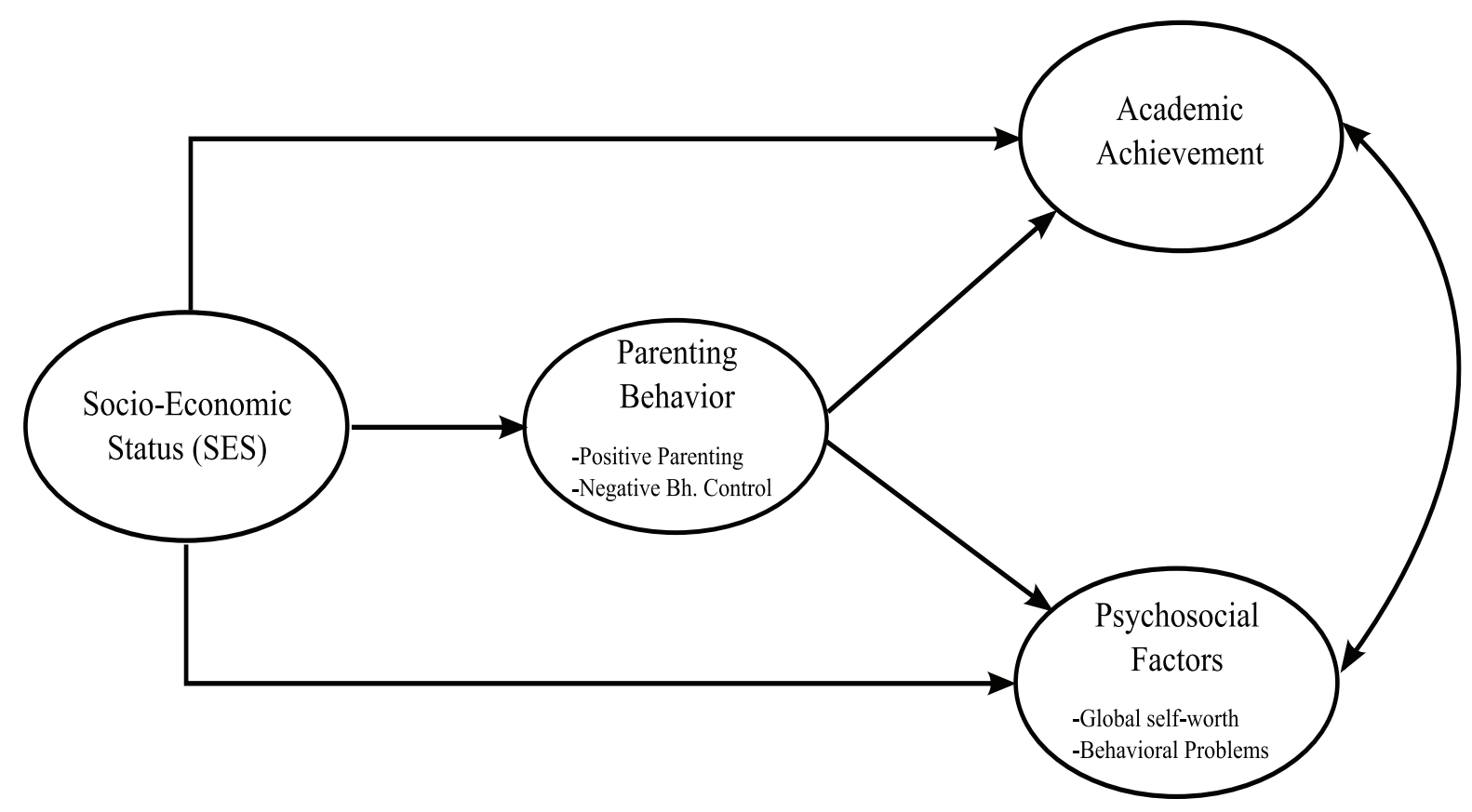

Figure 1: Hypothesized model of parenting behavior, SES, academic achievement and psychosocial functioning. Source: own work 
domains (Harter, 1993). Researchers have demonstrated that, generally, a variety of parental practices are inextricably linked to self-worth (Shaw, Bell, \& Gilliom, 2000). Among them, acceptance by the parents has been put forward as one of the central indicators for positive psychosocial adjustment in children. Parent-child relationships that are warm, affectionate and responsive are thought to facilitate children's confidence as well as their self-worth (Bean et al., 2003).

\section{Behavioral Problems}

Over the last two decades research has consistently linked child behavioral problems to ineffective parenting practices (Gelfand \& Teti, 1990). Punitive parental control is considered to be the use of arbitrary force with the goal of coercing children into conforming to parental demands. Coercive parental control is related to poor developmental outcomes showing positive relationships between punitiveness and adolescent's deviance, school misconduct, and externalizing behavioral problems.

\section{Academic achievement}

Although school and teacher efforts are extremely important, conditions outside the school hold another key to the promotion of academic achievement. Parenting is one of the factors that have been shown to significantly affect student performance and achievement. Research (Bean, Barber, $\&$ Crane, 2011) has consistently demonstrated an association between parenting support and greater academic success for children and adolescents. A number of positive outcomes have been associated with parenting responsiveness including child competence and scholastic achievement. Parents that maintain open communication, have warm and positive relationships with their offspring and those who monitor, using appropriate control techniques, have been demonstrated to have better adjusted children in terms of their academic development (Steinberg, Blatt-Eisengart, $\&$ Cauffman, 2006).

\section{Socioeconomic Status and Peruvian Culture}

Parenting differs across socioeconomic strata, which is mostly due to the different circumstances in which families live. For example, lower SES-parents generally provide more chaotic and unstructured environments than their higher SES counterparts (Evans, 2004). High SES-parents show higher engagement towards their offspring, talk more with them and provide higher levels of emotional and verbal responsiveness (Bradley \& Corwyn, 2002). Regarding the Peruvian case, the latest socioeconomic study (Asociación Peruana de Empresas de Investigación de Mercados [APEIM], 2010) shed light on the population distribution by socioeconomic status within Metropolitan Lima covering both rural and urban zones. The numbers confirm that half of the population $(50.8 \%)$ is within the traditional middle level. The inferior or marginal level consists of $44 \%$ of the Lima population. Despite its decrease over the last ten years, a significant number of families (18\% of the total population) live in a very precarious situation not able to meet the basic needs. The group characterized by high SES reaches $5.2 \%$ and has full access to private health services and first rate education.

When examining Peru, specifically Metropolitan Lima, major differences are encountered when comparing rural and urban areas on access to services, well-being indicators, socialization patterns, ethnicity and poverty. The latter trio comprises key variables when attempting to understand the manifold experiences of Peruvian children and their families (Ames \& Rojas, 2009).

\section{Method}

\section{Participants}

Participants for this study were 587 children of regular primary schools and their families. Children were attending sixth grade, over 45 classes in 17 different schools, located in Metropolitan Lima. Their ages ranged from 10.5 to 13.3 years old $(M=11.5 ; S D=0.41)$. There were 341 girls $(58.1 \%)$ 
and 246 (41.9\%) boys. Regarding the type of school, 290 (49.4\%) children attended private schools and 297 (50.6\%) public schools. Twenty-three (3.9\%) students repeated the $6^{\text {th }}$ grade.

Furthermore, 587 caregivers participated in the study. The vast majority of informants were mothers $(n=513), 39$ were fathers, 19 parents decided to complete the questionnaire together and 16 participants were other people in charge of raising the child, such as grandfathers or aunts. The mean age for male caregivers was $43.62(\mathrm{SD}=7.47)$ ranging from 27 to 78 years. Female Caregivers' age ranged from 26 to 68 , with a mean age of 40.10 $(\mathrm{SD}=6.35)$ years.

The Educational Level ranged from Non Education to Post-Grade and the mean level for fathers was Secondary Complete and for mothers Superior Technical Complete. In order to avoid categories with a small number of respondents, the ten categories of Educational Level were reduced to three referring to high, medium and low educational level. The SES variable was based on income, following previous research studies of the Peruvian Institute of Statistics. Overall, 38.5\% families belonged to middle SES $(n=226), 33.2 \%$ to low SES $(n=195)$ and $28.3 \%$ to high SES $(n$ =166). As regards family composition, 361 (61\%) parents were married, 136 (23\%) lived together unmarried, and the rest (12.2\%) was single, divorced or widow/widower.

\section{Instruments}

Some of the instruments used for this research were originally in English: the "Parental Behavior Scale", the "Perceived Competence Scale for Children" and the general and specific instructions of the "Number Facility" subtest. We translated the questionnaires from English to Spanish and back from Spanish to English. Three experts in English (Spanish speaking) commented on these versions and suggested changes were made. As regards other measures, a Spanish version was already available: the Orthography Achievement Test, Word and Pseudo word Reading of PROLEC-SE test and the Strengths and Difficulties Questionnaire.

\section{Parenting Behavior}

The Parental Behavior Scale ([PBS]; Van Leeuwen $\&$ Vermulst, 2004) assesses observable parental behavior and consists of 45 items. The original scale measure was translated in Spanish and psychometric properties were examined (Manrique Millones, Ghesquière, \& Van Leeuwen, 2014) resulting in good psychometric properties. Although the number of scales was condensed compared to the original instrument, the essence of the dimensionality is reflected in the remained scales: Positive Parenting (rules and positive parenting scales) and Negative Behavioral Control (discipline and harsh punishment scales). Parents rate the frequency of each behavioral item on a 5-point Likert scale ranging from never to always. They focus on their parenting behavior towards one target child.

\section{Spelling}

The Orthography Achievement Test (Dioses, 2001), was used to evaluate spelling. This tool assesses three separate aspects of general orthography: literal orthography, refers to the spelling rules established by the Royal Academy of Spanish Language addressing the knowledge of the correspondences between phonemes and graphemes; accentual orthography, denotes the correct use of the orthographic accents, and punctual orthography, indicates knowledge of the correct use of punctuation and intonation. Within this study scores ranged from 6 to 31 correct answers $(\mathrm{M}=$ 20.25; SD = 5.8).

\section{Reading}

A subtest of PROLEC-SE test (Ramos \& Cuetos, 1999) "Word and Pseudo-word Reading" was designed in order to assess reading. Basically, the instrument has two parts. During the first part, students are told to read out loud a list of 40 words as accurately and fast as possible. Similarly, in the second part, the pupil should read a list, but this time of pseudo-words. The evaluator scores each word. 


\section{Arithmetic}

"Number Facility" subtest of Ekstrom, French, and Harman (1976) battery was used to evaluate speed and accuracy in basic arithmetic operations. First, the student should solve as many addition operations as possible within 2 minutes, for two sets of 60 items, with three addends of one or two digits. In the second part, the pupil has to solve as many division operations as possible and finally, the child has to solve subtractions and multiplications, up to a total of 120 operations.

\section{Self-Worth}

The Perceived Competence Scale for Children ([PCS-C]; Harter, 1982) was used to evaluate selfworth through the assessment of a child's sense of competence across different domains. It is a self-report instrument consisting of 36 items distributed in six scales: scholastic competence, social acceptance, global self-worth, athletic competence, physical appearance and behavior. Children should choose one of two conflicting statements presented.

\section{Behavioral Problems}

The Strengths and Difficulties Questionnaire ([SDQ]; Goodman, 1997) was applied in order to measure the child's prosocial and problem behavior. The SDQ is a brief behavioral questionnaire for children between 3-16 years. It is a 25 -items scale in which the teacher or a parent has to mark for each psychological attribute (some of them positive and some negative) whether it is "Not True", "Somewhat True" or "Certainly True". In the current study the teacher or responsible tutor rated the SDQ. These 25 items are attributed to five subscales (emotional symptoms, conduct problems, hyperactivity / inattention, peer relationship problems, and prosocial behavior) with five items each and can have a score among 0 and 10 . For this study we used the total difficulties score, which is obtained by summing the scores from all the scales but the prosocial scale (based on 20 items ranging from 0 to 40 points).
Psychometric properties of our academic and psychosocial variables are acceptable and more descriptive information can be found in Manrique Millones, Van Leeuwen, and Ghesquière (2013).

\section{Socioeconomic Status}

This variable was measured with a socio-demographic questionnaire created specifically for this study. From the information obtained from the parent, such as family income per month, education, occupation, etc. and together with the information of the Peruvian Census of 2007, a Hollingshead Index was calculated resulting in a continuous variable ranging from $21.16 \$$ to $1,027.87 \$$ (per month per family) American Dollars.

\section{Procedure}

Data collection was performed as part of a larger study that explores the relationship among parenting, child achievement and psychosocial functioning within a Latino reality. Educational institutions or schools were randomly recruited in Metropolitan Lima (Manrique Millones, Van Leeuwen, \& Ghesquière, 2013). In the beginning of the study, a written notification was sent to the parents through the school, explaining the objectives of the study and inviting them to participate.

After receiving authorization from the schools, an information letter in a sealed envelope was sent to parents of private schools. The letter gave detailed information about the study. Instead, in public schools a talk was given to parents and an oral consent was received. Also, the collaboration of $6^{\text {th }}$ grade tutors was asked in order to fill out the SDQ.

Children were tested in three sessions of $45 \mathrm{~min}$ utes each; all tests were administered collectively with exception of reading that was evaluated individually taking the pupil to a separate room. The tasks were administered in a fixed order: in the first session arithmetic and spelling were assessed with a 10 minute break between testing, in the second session intelligence and reading were administered following the same procedure, and in the third selfworth and behavioral problems were evaluated. 


\section{Data Analysis}

Structural equation modeling (SEM) was performed to test the hypothesized models using LISREL 8.8 (Jöreskog \& Sörbom, 2004). Model fit was evaluated through the inspection of several fit indexes: the chi squared statistic $\left(\chi^{2}\right)$, the root mean squared error of approximation (RMSEA), and the comparative fit index (CFI). In order for a model to have a good fit, the RMSEA should be equal or lower than 0.06, and the CFI should be close to 0.95 or higher (Hu \& Bentler, 1999). RMSEA values lower than .08 and a CFI statistic equal to .90 or higher indicate an acceptable fit (Byrne, 1998).

Four models were made as depicted in Figure 1, each with four latent or unobserved variables: socioeconomic status, academic achievement, parenting behavior: consisting of two dimensions (negative behavioral control or positive parenting) and psychosocial functioning, comprising two dimensions (global self-worth or behavioral problems). Model 1 and 2 included behavioral problems as the main psychosocial dimension. A path was drawn from positive parenting towards two child variables: academic achievement and behavioral problem (Model 1). In model 2 from negative behavior control a path was drown towards academic achievement and behavioral problems. Model 3 and 4 comprised global self- worth as the main dimension of psychosocial functioning. From positive parenting a path was drawn towards academic achievement and global self-worth (Model 3) and in model 4 a path from negative behavior control towards the aforementioned child outcomes. Socioeconomic status was included in all four models affecting child variables and parenting dimensions.

\section{Results}

\section{Descriptive Statistics}

Descriptive statistics (means, standard deviations and ranges) and distributional properties (skewness and kurtosis) for each of the scales are presented in Table 1. Data screening of the variables indicated partial data non-normality. Therefore, in all models the asymptotic covariance matrix was used as input and the Satorra-Bentler Scaled chi-square test was inspected ([SBS- $\left.\chi^{2}\right]$; Satorra \& Bentler, 1994).

\section{Path Models Including Behavioral Problems}

\section{Positive Parenting}

Testing of the first model (Figure 2) yielded an adequate fit $\mathrm{SBS}-\chi^{2}(25)=30.54, p=0.2 ; \mathrm{RM}$ $\mathrm{SEA}=0.019 ; \mathrm{CFI}=1$. There were significant and positive paths from socioeconomic status to academic achievement $(\beta=0.29)$, and to positive parenting $(\beta=0.19)$, and a significant negative path from SES to behavioral problems

\section{TABLE 1}

Descriptive Statistics of the Scales

\begin{tabular}{lccccc}
\hline & Mean & SD & Skewness & Kurtosis & Range \\
\hline Parenting Behavior & & & & & \\
$\quad$ Positive Parenting & 4.37 & 0.46 & -1.12 & 1.61 & $2.56-5$ \\
$\quad$ Negative Behavioral Control & 2.46 & 0.67 & 0.31 & -0.04 & $1-4.68$ \\
Psychosocial Factors & & & & & \\
$\quad$ Global Self-Worth & 3.17 & 0.23 & -0.75 & 0.25 & $1-4$ \\
$\quad$ Behavioral Problems & 10.66 & 0.26 & 0.47 & 0.01 & $0-33$ \\
Academic Performance & & & & & \\
$\quad$ Spelling & 20.25 & 5.8 & -0.16 & -0.96 & $6-31$ \\
$\quad$ Arithmetic & 64.14 & 27.31 & 1.24 & 2.65 & $14-201$ \\
$\quad$ Reading & 100.14 & 24.32 & 0.73 & 1.58 & $39.13-247.5$ \\
\hline
\end{tabular}

Source: own work 


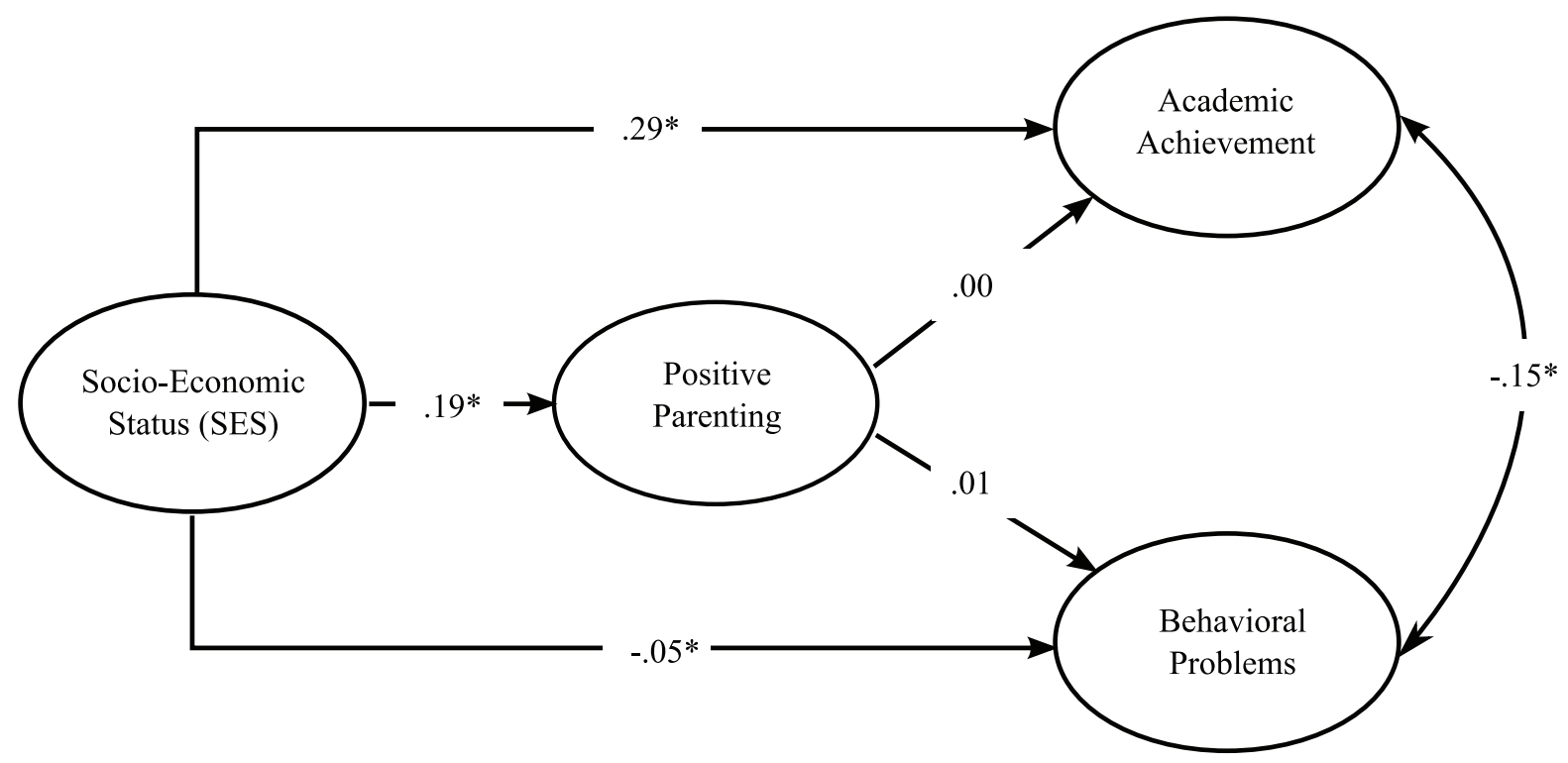

Figure 2. Standardized beta coefficients for Model 1.

Note. * $=$ Parameters significant with $p<0.05$

Source: own work

$(\beta=-0.05)$. Behavioral problems and academic achievement were negatively correlated $(r$ $=-0.15)$. There were no significant paths from positive parenting to problem behavior nor to academic achievement.

\section{Negative Behavioral Control}

The second estimated model (Figure 3) yielded an adequate fit SBS- $\chi^{2}(25)=32.85, p=0.13$; RM$\mathrm{SEA}=0.023 ; \mathrm{CFI}=0.99$. The model showed $\mathrm{a}$

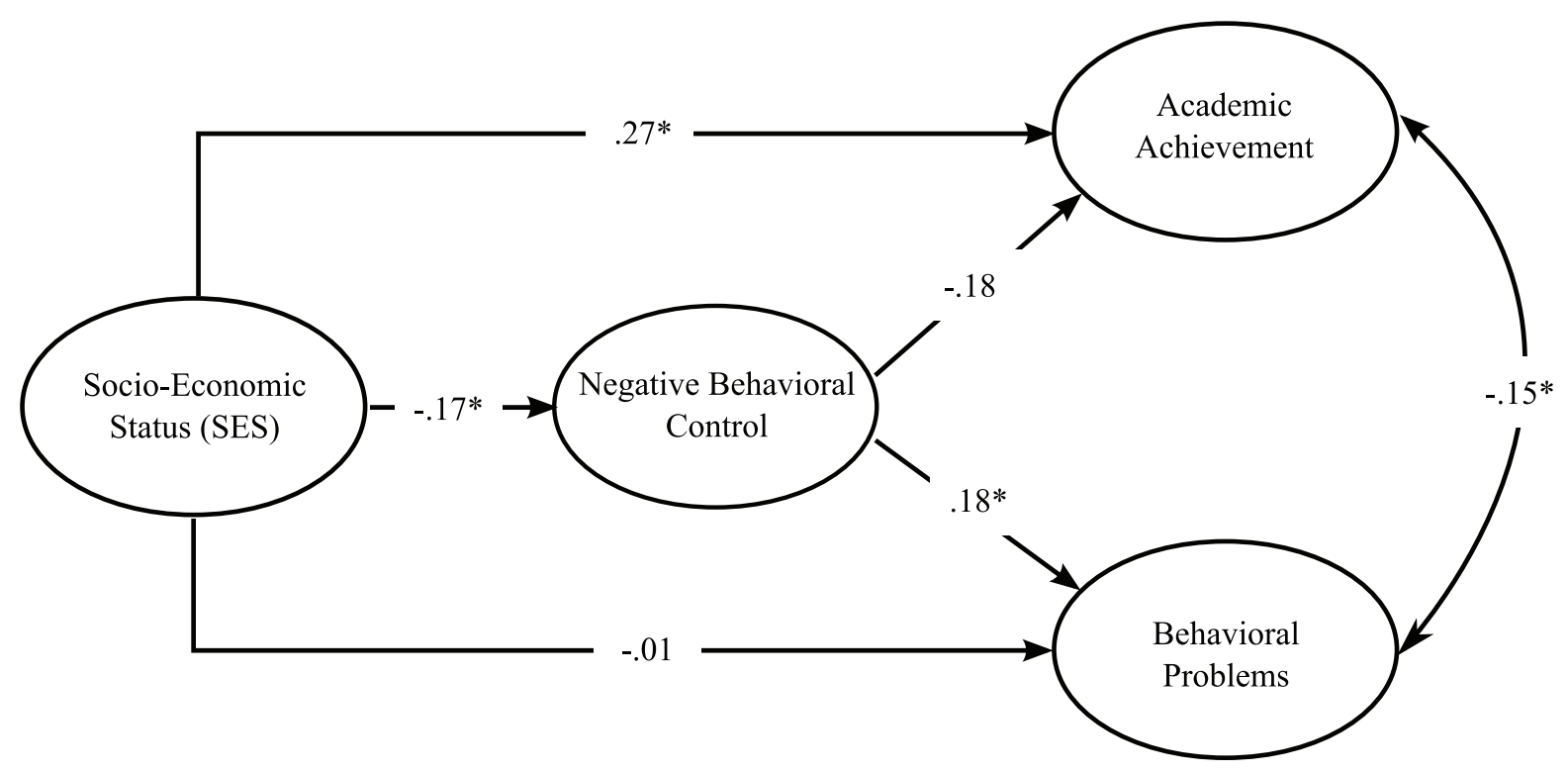

Figure 3: Standardized beta coefficients for Model 2.

Note. $*$ = Parameters significant with $\mathrm{p}<0.05$

Source: own work 
direct and positive effect of socioeconomic status on academic achievement $(\beta=0.27)$ and a negative effect on to negative behavioral control $(\beta=-0.17)$. SES had an indirect effect on behavioral problems via negative behavioral control $(\beta=0.18)$. Behavioral problems were significantly but negatively correlated with academic achievement $(r=-0.15)$. There were no significant paths from negative behavioral control to academic achievement.

\section{Path Models Including Self-Worth}

\section{Positive Parenting}

The estimated third model (Figure 4) yielded an adequate fit SBS- $\chi^{2}(25)=46.18, p<0.05$; RM$\mathrm{SEA}=0.038 ; \mathrm{CFI}=0.98$. There were significant and positive paths from socioeconomic status to academic achievement $(\beta=0.20)$ and positive parenting $(\beta=0.21)$. Socioeconomic status had an indirect effect on global self-worth through positive parenting $(\beta=0.14)$. Finally, self-worth significantly correlated with academic achievement $(r=0.29)$. There was no significant path from positive parenting to academic achievement.

\section{Negative Behavioral Control}

The estimated model 4 (Figure 5) yielded a moderate global fit SBS- $\chi^{2}(25)=93.22 ; p<0.05$; RMSEA $=0.059 ; \mathrm{CFI}=0.99$. The fourth model showed a significant direct and positive effect of socioeconomic status on academic achievement $(\beta=0.17)$; whereas it was negatively related to negative behavioral control $(\beta=-0.24)$. SES had an indirect effect on global self-worth via negative behavioral control $(\beta=-0.18)$. We did find significant paths from negative behavioral control to academic achievement $(\beta=-0.14)$. Finally self-worth was significant positively correlated with academic achievement $(r=0.27)$.

\section{Discussion}

The main purpose of this study was to analyze relationships among child (academic achievement and psychosocial functioning), contextual (SES) and parental (positive parenting and negative behavioral control) factors within a Peruvian reality. We tested four models and the results showed a good fit for all four of them. Moreover, in line with previous

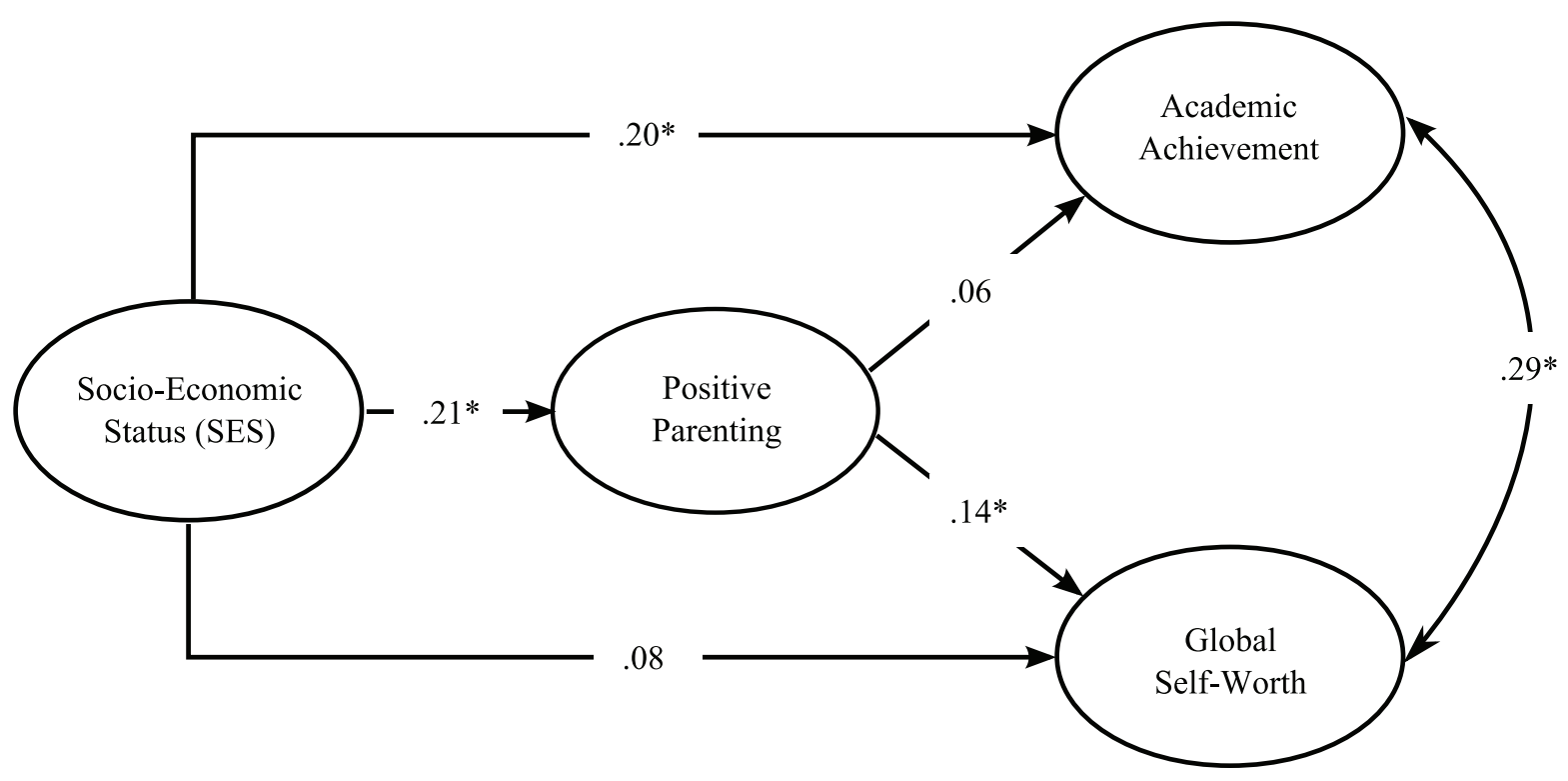

Figure 4: Standardized beta coefficients for Model 3.

Note. * $=$ Parameters significant with $p<0.05$.

Source: own work 
research, our hypothesized theoretical associations were confirmed.

\section{Associations between SES, Parenting and Child Outcome}

Structural Equation Modeling (SEM) results showed an effect of socioeconomic status on both parenting dimensions: a higher SES was associated with more positive parenting and with less negative behavioral control. It is often found in literature that belonging to a certain socioeconomic level exerts great influence on children's behavior. Estimates of the overall socioeconomic status often provide little information about the processes through which socioeconomic status exerts its influence on family and child mental health. It is likely then that the social and cultural beliefs of parents influence the meaning that they give to a specific child behavior, the ways in which they respond to it, their expression and its results. It is possible that parents with a different SES interpret the same child behavior differentially, according to their degree of internal tolerance. As many studies state, SES has legitimacy as a contextual variable within the parenting and child well-being research field (De Garmo, Forgatch, \& Martines, 1999).

In general, research studies have consistently examined how SES is related to parenting behaviors. In contrast, less work on how factors as parenting behavior might function as links between SES and child outcomes has been made (Halle, KurtzCostes, \& Mahoney, 1997). Results obtained in our study and in line with previous literature has shown the indirect effect of SES through parenting on children's outcome. In a national cross-sectional study with non-Hispanic European American and African American, Davis-Kean (2005) found that the socioeconomic factors (e.g. parent's education or income) were related indirectly to children academic achievement through parent's belief and behavior.

We found differential effects of the warmth/ support and control dimension of parenting in the prediction of child outcome. Positive parenting only was related to global self-worth, but not to behavioral problems and academic achievement whereas negative behavioral control was related to self-worth, problem behavior and academic achievement.

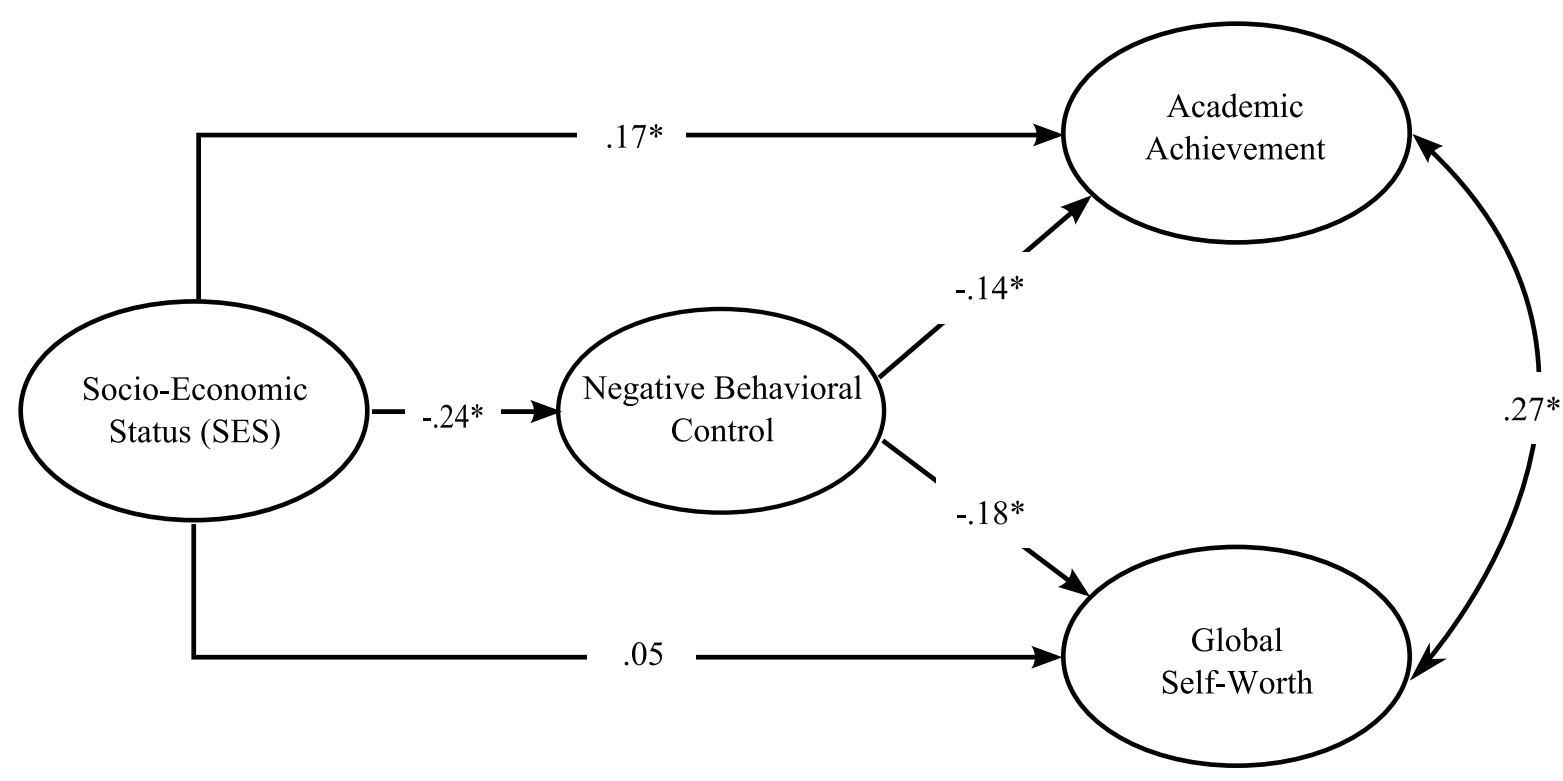

Figure 5: Standardized beta coefficients for Model 4.

Note. * = Parameters significant with $p<.05$.

Source: own work 


\section{Associations between Academic Achievement and Psychosocial Factors}

We found a strong and positive relationship between self-worth and academic achievement, meaning that children that have higher levels of selfworth are more likely to have academic success or the other way around, academic success is the source of a positive self-worth. Research on selfworth has shed informative light on the development of family relationships, but its role regarding academic achievement is less clear (Franklin \& Streeter, 1995). Nevertheless, there are some studies that have documented the relationship between self-worth and academic achievement in adolescent samples (DuBois, Bull, Sherman, \& Roberts, 1998). Results obtained in recent decades comparing students with high and low school performance, imply that the latter are characterized by low selfworth and in extreme cases delinquent behavior, rebellious feelings of inadequacy and lack of career prospects (Harter, 1993). Studies in educational settings confirm the effect of perceived competence on school performance. Individuals with positive expectations of personal efficacy have better school performance than those with feelings of low selfworth and personal ineffectiveness (DuBois et al., 1998). The influence of the social environment, particularly the family, plays a central role in the evaluation process underlying self-worth. If a teen is able to demonstrate competence in certain domains, this will result in social and family approval, affecting favorably his/her feelings of self-worth (Harter, 1993). The observed results confirm this relationship and reinforce the findings of research conducted in this area (Franklin \& Streeter, 1995).

Results showed a meaningful negative association between children's behavioral problems and academic achievement, meaning that disruptive behavior contributes to low academic achievement or academic success contributes to dilute behavioral problems.

Behavioral problems are a serious and difficult problem for both education and mental health of students and parents whose children fail in school performance, despite their efforts and expecta- tions. Most students with disruptive behaviors have slight alterations in their cognitive, psychomotor and emotional aspects, but, generally, they are not assigned to specific diagnostic categories such as mental retardation, attention deficit disorder or specific learning disorders (Jadue, 2002).

Each student presents different behavioral and cognitive-affective characteristics. Schools in general provide a teaching system for "normal" or "average" children that have no idiosyncrasy and show no alteration, deviation, or deficiency in any aspect of their development. As a consequence, children who, for some reason, deviate or move away from this "average" are at great risk of underachievement and school failure (Save the Children, 2007-2009). A student at "risk" does not mean a 'retarded' or 'disabled' student. The designation "at risk" refers to personal characteristics or circumstances of the school environment, family or social context that predispose the child to negative experiences such as desertion, underachievement, emotional disorders, conduct disorder, substance abuse, etc.

\section{Implications of this Study for the Peruvian Context}

Currently in Peru, many students have poor school performance together with behavioral disturbances (Oliveros et al., 2009). Many of them do not get the professional help they need inside or outside the school. When not treated appropriately, not only problems in the learning process of these students occur, but they also affect the ability of teachers to teach their peers. Many teachers feel overwhelmed by the emotional and behavioral difficulties that these students have in class. Preschool, primary or secondary teachers, sooner or later will face students who have behavioral problems, and influence their classmates.

Parents and teachers share a concern about the problem behavior that the student presents. Parents inevitably worry about how the child behaves and this concern is compounded with feelings of frustration and anger when his/her school progress is too slow or scarce and criticism of other parents and/or teachers may increase. It should be noted 
that in many cases, students who disturb others in the classroom have not yet learned a proper way to make friends and establish relationships (Ronk, Hund, \& Landau, 2011; Sturaro, van Lier, Cuijpers, $\&$ Koot, 2011). These children are generally unhappy, isolated by their classmates and unpopular among teachers.

Calkins and Dedmon (2000) demonstrated that children who are disobedient, destructive, impulsive, and show aggressive behavior are at high risk of being rejected by their peers and develop associated problems such as dropping out or school failure.

Finally, we demonstrated a positive link between negative behavioral control and child behavioral problems, meaning that the more use of harsh punishment or punitive discipline the higher behavioral problems in children, although we cannot make any causal inferences, given the cross-sectional nature of the data.

Ramírez (2002) suggests that inadequate parenting practices like for example, negative affect, non-physical punishment, authoritarian control and emphasis on achievement are associated to both externalizing and internalizing child problem behavior. Specifically, negative affect predicts aggressive behavior, attention problems, authoritarian control, anxiety/depression, social problems.

One of the most important implications of this study is the role played by parents in child outcomes. As our models showed, parenting behaviors can be negatively or positively associated to child academic achievement or psychosocial functioning. The support, affection and appropriate interactions may help the cognitive and psychosocial development during childhood. Similarly, care, health and development are related to acceptance and openness that parents may show to their children. Inadequate parenting practices during childhood may be risk factors for cognitive or socio-affective problems. Parents should be guided to create prevention strategies, generating spaces to develop social skills.

\section{Limitations of this Study}

Some limitations can be found in the present study, for example regarding the nature of the data. Cross-sectional data involves measuring our variables at a single point of time and gives us a great overview of conditions present at that instant. Nevertheless, it doesn't allow us to describe development or changes in our population. Another important limitation is that despite the support and collaboration of the teachers, by filling in the SDQ, we could not include any variable regarding teacher or class characteristics, due to time constraints. Finally, although parenting is a bi-directional process, we have not investigated bi-directionality in the current study. It is important that future research efforts fill out these voids in order to have more tools that allow us to establish causality and generalizations.

\section{References}

Ames, P., \& Rojas, V. (2009). Childhood, transitions and well-being in Peru: A literature review. Young Lives Technical Note, 16, 1-32.

Asociación Peruana de Empresas de Investigación de Mercados. (2010). Niveles Socioeconómicos 2010, Lima Metropolitana. Peruvian Association of Marketing Research Report. Retrieved from http://www. apeim.com.pe/niveles.html

Bean, R. A., Barber, B. K., \& Crane, D. R. (2011). Academic, internalized, and externalized problems in ethnically diverse adolescents: The contributions of parental support, behavioral control and psychological control. Texas Tech University, Lubbock, Texas, USA. Manuscript submitted for publication.

Bean, R. A., Bush, K. R., McKenry, P. C., \& Wilson, S. M. (2003). The impact of parental support, behavioral control, and psychological control on the academic achievement and self-esteem of African American and European American adolescents. Journal of Adolescent Research, 18(5), 523-541.

Bradley, R. H., \& Corwyn, R. F. (2002). Socioeconomic status and child development. Annual Review of Psychology, 53(1), 371-399.

Byrne, B. (1998). Structural Equation Modeling with PRELIS, LISREL and SIMPLIS: Basic concepts, applications and programming. New Jersey, NJ: Lawrence Erlbaum Associates. 
Calkins, S., \& Dedmon, S. (2000). Physiological and behavioral regulations in two year old children with aggressive/destructive behavior problems. Journal of Abnormal Child Psychology, 28(2), 103-118.

DuBois, D. L., Bull, C. A., Sherman, M. D., \& Roberts, M. (1998). Self- esteem and adjustment in early adolescence: A social-contextual perspective. Journal of Youth and Adolescence, 27(5), 557-583.

Evans, G. (2004). The environment of childhood poverty. American Psychologist, 59(2), 77-92.

Franklin, C., \& Streeter, C. L. (1995). Assessment of middle class youth at-risk to dropout: School, psychological and family correlates. Children $\mathbb{E}$ Youth Services Review, 7(3), 433-448.

Gelfand, D. M., \& Teti, D. M. (1990). The effects of maternal depression on children. Clinical Psychology Review, 10(3), 329-353.

Harter, S. (1993). Causes and consequences of low self-esteem in children and adolescents. In R. F. Baumeister (Eds.), Self-esteem: The puzzle of low self-regard (pp. 87-116). New York: Plenum Press.

Hu, L., \& Bentler, P. M. (1999). Cutoff criteria for fit indexes in covariance structure analysis: Conventional criteria versus new alternatives. Structural Equation Modelling, 6(1), 1-55.

Jadue, G. (2002). Factores psicológicos que predisponen al bajo rendimiento, al fracaso y a la deserción escolar. Estudios Pedagógicos, 28, 193-204.

Jöreskog, K., \& Sörbom, D. (2004). LISREL version 8.7. Lincolnwood, IL: Scientific Software International.

Keegan, M. (2005). Social-demographic, school, neighborhood, and parenting influences on the academic achievement of Latino young adolescents. Journal of Youth and Adolescence, 34(2), 163-174.

Leyendecker, B., Harwood, R. L., Compazrini, L., \& Yalcinkaya, A. (2005). Socioeconomic status, ethnicity and parenting. In T. Luster \& L. Okagaki (Eds.), Parenting: An ecological perspective (2nd ed., pp. 319-342). Mahwah, NJ: Lawrence Erlbaum.

Manrique Millones, D., Ghesquière, P., \& Van Leeuwen, K. (2014). Evaluation of a Parental Behavior Scale in a Peruvian Context. Journal of Child and Family Studies, 23(5), 885-894.

Manrique Millones, D. L., Van Leeuwen, K., \& Ghesquière, P. (2013). Associations between psychosocial functioning and academic achievement: The Peruvian case. Universitas Psychologica, 12(3), 725 737. doi:10.11144/Javeriana.UPSY12-3.apfa

Mewse, J., Eiser, R., Slater, A., \& Lea, S. (2004). The smoking behavior of adolescents and their friends: Do parents matter? Parenting: Science and Practice, 4, 41-72.

Oliveros, M., Figueroa, L., Mayorga, G., Cano, G., Quispe, Y., \& Barrientos, A. (2009). Bullying in secondary national schools of Perú. Revista Peruana de Pediatría, 62(2), 68-78.

Ramírez, M. (2002). Prácticas de crianza de riesgo y problemas de conducta en los hijos. Apuntes de Psicología, 20(2), 273-282.

Ronk, M. J., Hund, A. M., \& Landau, S. (2011). Assessment of social competence of boys with attentiondeficit/hyperactivity disorder: Problematic peer entry, host responses, and evaluations. Journal of Abnormal Child Psychology, 39(6), 829-840.

Save the Children. (2007-2009). Participación social para la educación en zonas de pobreza en el Perú. Retrieved from http://www.savethechildren.org. pe/web/upload/publicacion

Shaw, D. S., Bell, R. Q., \& Gilliom, M. (2000). A truly early starter model of antisocial behavior revisited. Clinical Child and Family Psychology Review, 3(3), 155-172.

Steinberg, L., Blatt-Eisengart, I., \& Cauffman, E. (2006). Patterns of competence and adjustment among adolescents from authoritative, authoritarian, indulgent and neglectful homes: A replication in a sample of serious juvenile offenders. Journal of Research on Adolescence, 16(1), 47-58.

Sturaro, C., van Lier, P. A. C., Cuijpers, P., \& Koot, H. M. (2011). The role of peer relationships in the development of early school-age externalizing problems. Child Development, 82(3), 758-765. 